\title{
Ética nas ações educativas e de cuidado em saúde orientadas pela Educação Popular
}

Patricia Serpa de Souza Batista ${ }^{(a)}$

Eymard Mourão Vasconcelos ${ }^{(b)}$

Solange Fátima Geraldo da Costa(c)

Batista PSS, Vasconcelos EM, Costa SFG. Ethics in educational and health care actions oriented by popular education. Interface (Botucatu). 2014; 18 Supl 2: 1401-1412.

This study aims to analyze ethics in educational and care actions oriented by Popular Education in Health, based on the extensionists experiences of the Popular Education and Family Health Care Project. This is a qualitative research done with ten extensionists in the Maria de Nazaré Community, João Pessoa-PB. The empirical material was collected through interviews and participant observation and analyzed by content analysis technique. The reflections showed the importance of valuing subjectivity, sensitivity, take the lead of your own life, affective bonding and loveliness in the ethical acts directed at health care family. This study brings a conception of ethics that transposes the directed act to compliance with ethics codes, usual in health.

Keywords: Ethics. Health. Care. Popular Education in Health.
Este estudo objetiva analisar a ética nas ações educativas e de cuidado orientadas pela Educação Popular em Saúde, com base na experiência de extensionistas do Projeto Educação Popular e Atenção à Saúde da Família. Trata-se de estudo qualitativo realizado com dez extensionistas na Comunidade Maria de Nazaré, João Pessoa-PB. O material empírico foi coletado através das técnicas de entrevista e observação participante e analisado mediante técnica de Análise de Conteúdo. As reflexões evidenciaram a importância da valorização da subjetividade, da sensibilidade, do protagonismo, do vínculo afetivo, da defesa dos direitos humanos, da amorosidade, no agir ético direcionado ao cuidado à saúde da família. Esse estudo traz uma concepção de ética que transpõe o agir direcionado ao cumprimento de códigos de ética, usual na saúde.

Palavras-chave: Ética. Saúde. Cuidado. Educação Popular em Saúde.

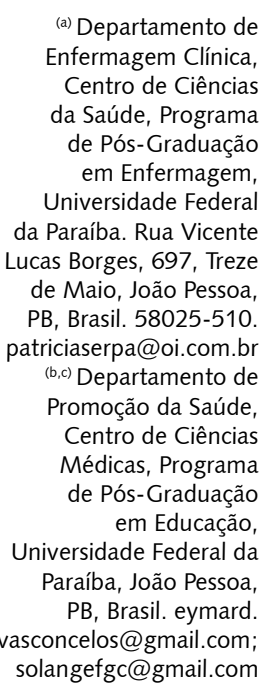

(a) Departamento de fermagem Clínica, a Saúde, Programa de Pós-Graduação em Enfermagem, da Paraíba. Rua Vicente Lucas Borges, 697, Treze de Maio, João Pessoa, PB, Brasil. 58025-510. (biaserpa@oi.com.br Promoção da Saúde, Centro de Ciências Médicas, Programa Pós-Graduação iversidade Federal da Paraíba, João Pessoa, vasconcelos@gmail.com; solangefgc@gmail.com 


\section{Introdução}

A ética é considerada como teoria ou ciência que estuda o comportamento moral do ser humano1, ou seja, o comportamento adequado diante dos valores socialmente aceitos pelos grupos a que o ser humano pertence. O comportamento moral relaciona-se aos modos de agir cotidianos, às decisões que vão sendo tomadas, de acordo com os valores e os princípios adequados àquela sociedade específica.

A ética tem sido valorizada por diferentes áreas do conhecimento, ocupando espaço nas discussões sobre meio ambiente, política, comunicação, saúde, educação, entre outros. Na educação, especialmente na Educação Popular, a ética é considerada de forma específica. A Educação Popular compreende elementos eticopolíticos relacionados com a construção de relações equitativas e justas mediante uma pedagogia dialógica, crítica, que busca o desenvolvimento pleno das capacidades humanas cognitivas, emocionais e valorativas ${ }^{2}$. Em seu livro Pedagogia da Autonomia, Freire ${ }^{3}$ discorre sobre uma ética universal do ser humano, de valorização da vida e da dignidade humana, uma ética que condena os interesses do lucro das sociedades capitalistas, estando direcionada à conscientização do oprimido, tornando o processo educativo uma prática para a liberdade.

A ética da libertação e da solidariedade proposta pelo educador Paulo Freire relaciona-se ao compromisso de lutar pela dignidade do oprimido e pela justiça social ${ }^{4}$. É uma ética que se encontra firmada nos valores da solidariedade, da amorosidade, do respeito à diversidade e aos saberes, da valorização da autonomia coletiva, da perseverança na construção de mudanças ${ }^{5}$.

$\mathrm{Na}$ área da saúde, a ética também tem sido bastante enfocada, entretanto, especialmente na formação acadêmica, encontra-se muito direcionada a uma ética normativa profissional, isto é, do agir segundo o dever. Essa ética toma por base o cumprimento de códigos de ética profissionais específicos que norteiam o agir no exercício das profissões em saúde.

No campo da saúde, a Educação Popular atua como estratégia de superação da grande distância que existe entre o serviço de saúde e o saber científico, de um lado e, de outro, a dinâmica que envolve o adoecimento e a cura. Tem significado uma importante referência teórica e metodológica para a reorientação da atenção à saúde a partir da construção compartilhada e dialogada de práticas de cuidado e promoção da saúde, com as várias pessoas e grupos sociais envolvidos nas questões trabalhadas. Assim, vem sendo considerada um instrumento de construção para saúde mais integral e adequada à vida da população $0^{6}$. A Educação Popular traz para o trabalho em saúde, por meio da problematização das situações enfrentadas, uma ampliação das ações de cuidado, prevenção e promoção da saúde, integrando-as na luta por melhores condições de vida e por uma sociedade mais justa e solidária.

As práticas de Educação Popular têm sido incorporadas na formação universitária em saúde, principalmente através das atividades de extensão. A extensão tem representado o campo institucional da vida universitária que tem conseguido apoiar e organizar grande parte das iniciativas emergentes que expressam propostas e práticas pedagógicas que criticam o que é dominante e bem estabelecido e que buscam novas formas de atuação social. Tem significado importante espaço de fortalecimento institucional do movimento renovador presente na universidade, gerando questões, propostas, pesquisas, saberes e movimentos que irradiam para o ensino de graduação e pós-graduação. Tem-se assistido, assim, à criação e reorganização de muitas disciplinas, principalmente aquelas voltadas para o ensino de práticas comunitárias, que estão se estruturando a partir dos princípios da Educação Popular. Isto vem sendo particularmente importante no ensino em saúde, cuja extensão orientada pela Educação Popular tem se mostrado mais organizada e atuante que em outros setores, tendo, inclusive, tomado a frente na organização da Articulação Nacional de Extensão Popular (ANEPOP) em 20057.

Este estudo está associado a essa perspectiva de extensão, denominada de extensão popular ${ }^{8}$. A extensão popular apresenta uma base já bem estruturada na Universidade Federal da Paraíba (UFPB), atuando em comunidades periféricas do município de João Pessoa-PB. Dentre as práticas de Extensão Popular da UFPB, há o Projeto Educação Popular e Atenção à Saúde da Família (PEPASF) que atua na Comunidade Maria de Nazaré, há cerca de quinze anos. É desenvolvido principalmente mediante ações 
educativas e de cuidado em saúde no acompanhamento interdisciplinar de estudantes a famílias e atividades coletivas desenvolvidas com crianças, idosos e moradores em geral, no espaço comunitário.

Uma das pesquisadoras deste estudo atua nesse Projeto desde o ano de 2006, desenvolvendo atividades semanais com o grupo de extensionistas e a população local. Nele, tem-se observado a importância das considerações éticas na reorientação de suas práticas de cuidado e como essas práticas ali reorientadas são inovadoras e significativas em apontar caminhos de uma atenção mais integral e humanizada. Como esta pesquisadora participa também do Núcleo de Estudos e Pesquisas em Bioética da UFPB e vem estudando o tema da ética em saúde desde o seu mestrado, em 2002, ela percebeu a importância destas considerações para o debate teórico que se vem fazendo sobre os desafios éticos da atenção primária à saúde no contexto atual do Sistema Único de Saúde.

A construção de novos formatos para a atenção em saúde não pode depender apenas da formulação de propostas pelos grandes estudiosos do campo ou pelas lideranças institucionais. É preciso valorizar os saberes construídos em práticas estruturadas, a partir de iniciativas de profissionais, docentes, estudantes e movimentos sociais que vêm tentando superar os entraves a uma assistência à saúde mais integral e ética. A partir dos saberes acumulados nesses quinze anos do PEPASF, buscou-se discutir, nesta pesquisa, a forma como a ética da Educação Popular reorienta as ações educativas e de cuidado, inseridas em uma comunidade de periferia urbana.

Cabe ressaltar que as práticas de Educação Popular em Saúde vêm ganhando notoriedade no Sistema Único de Saúde e se orientam por princípios diferentes daqueles que norteiam cuidados tradicionais em saúde, os quais, em geral, ainda se encontram muito firmados em uma perspectiva biologicista e numa ética de abordagem normatizadora, baseada no cumprimento de códigos de ética específicos. Embora se observe um número representativo de pesquisas sobre a ética no cuidado em saúde e várias outras envolvendo o tema da ética na Educação Popular, não foi possível identificar, na bibliografia disponível, nenhum estudo envolvendo o tema ética na Educação Popular em Saúde e muito menos sobre sua implicação na reorientação do cuidado em saúde. Neste sentido, o estudo sobre a ética da Educação Popular em Saúde e suas implicações para as práticas comunitárias de saúde é pioneiro no campo da saúde coletiva e da pedagogia.

Com base nessas considerações, este estudo tem o objetivo de analisar a ética nas ações educativas e de cuidado orientadas pela Educação Popular em Saúde, com base na experiência de extensionistas do Projeto Educação Popular e Atenção à Saúde da Família.

\section{Metodologia}

Trata-se de uma pesquisa de campo, de natureza qualitativa, realizada na Comunidade Maria de Nazaré, localizada no Bairro Funcionários III, município de João Pessoa-PB. Participaram da pesquisa dez extensionistas, sendo cinco professores e cinco estudantes que estavam vinculados ao PEPASF. Os critérios de inclusão abrangeram os aspectos: ter idade superior a dezoito anos, participar do PEPASF há um período mínimo de um ano e aceitar participar da pesquisa. Vale ressaltar que este estudo trata de recorte de uma tese de doutorado que contou com a participação de estudantes, professores, lideranças comunitárias e moradores que estavam vinculados às ações do Projeto, durante o período de coleta de dados.

A coleta do material empírico foi realizada no período de junho a julho de 2010, mediante entrevista, gravada e transcrita para análise e através da observação participante. Os dados obtidos foram analisados qualitativamente por meio da técnica de análise de conteúdo proposta por Bardin ${ }^{9}$, que segue as fases de pré-análise, exploração do material, tratamento dos resultados obtidos e interpretação.

Foram considerados os princípios éticos das pesquisas com seres humanos, conforme a Resolução n 196/96 do Conselho Nacional de Saúde, em vigor no país no período da apreciação do projeto ao Comitê de Ética em Pesquisa. O projeto foi encaminhado ao Comitê de Ética em Pesquisa do Centro de Ciências da Saúde da UFPB e obteve parecer favorável sob o protocolo nº 091/2009. 
O Termo de Consentimento Livre e Esclarecido foi assinado pelos participantes da pesquisa, sendo garantidos a autonomia e o anonimato.

Para garantir o anonimato dos participantes, os relatos foram assinalados com letra " $E$ ", quando referia-se a Estudante, e "P", a Professor, seguido do número de ordem da realização das entrevistas.

\section{Resultados e Discussão}

No que se refere à caracterização dos participantes do estudo, dos cinco docentes pesquisados, quatro são do sexo feminino e um, do sexo masculino; dois realizam atividades acadêmicas no Curso de Fisioterapia; um, no Curso de Medicina; um, no Curso de Psicologia, e um, no Curso Técnico de Enfermagem da UFPB. Todos têm idade entre trinta e nove e cinquenta e um anos e têm pós-graduação: um é doutor, três são doutorandos e um é mestre. Todos os participantes vêm desenvolvendo atividades no PEPASF por um período que varia entre quatro e treze anos. Com relação aos cinco estudantes participantes, a maioria é do sexo feminino, têm idade entre vinte e vinte e sete anos, e vêm realizando atividades no PEPASF, por um período que varia entre um e três anos.

\section{O modo ético das ações educativas e de cuidado orientadas pela Educação Popular em Saúde na Comunidade Maria de Nazaré}

O modo ético como o cuidado e as ações educativas norteadas pela Educação Popular em Saúde estruturam-se na comunidade é definido, no processo de relação com as pessoas e os grupos comunitários. Não se trata de uma relação qualquer, mas uma relação marcada pelo vínculo afetivo, pelo diálogo orientado pela teoria da Educação Popular, pela problematização das questões suscitadas nesse diálogo e pela preocupação com a justiça social.

É pertinente ressaltar que há uma gradação de vínculo e de profundidade de diálogo dos estudantes com a população comunitária. Os aspectos aqui discutidos não são seguidos por todos os estudantes, mas representam uma tentativa de perceber os elementos mais marcantes dessa ética.

Trata-se de um modo ético de cuidar diferenciado, pois não se relaciona apenas a uma concepção de ética normativa, pré-estabelecida, pautada em códigos de ética específicos. A abordagem de cuidado em saúde no PEPASF segue uma concepção de ética delineada coletivamente, de acordo com cada caso específico, a partir da problematização de situações concretas. Portanto, não é possível seguir continuamente, no cotidiano das ações de saúde, o cumprimento de normatizações pré-estabelecidas.

A experiência do PEPASF evidenciou o vínculo afetivo como elemento estruturante do agir ético de estudantes. Como refere o depoimento a seguir:

“[...] um dos elementos éticos da Educação Popular em Saúde é o compromisso verdadeiro, que a gente pode cristalizar no vínculo. O PEPASF é fantástico nisso, e isso é a raiz profunda de qualquer ética, porque, por exemplo, a partir do momento em que eu chegava àquelas famílias, a cada visita, a cada conversa na insistência de continuar visitando-as, de continuar escutando os desabafos da comunidade assim como um todo, a gente vai criando um vínculo, uma amizade". (E3)

Como ficou claro no discurso, a continuidade do acompanhamento às famílias tende a promover o fortalecimento do vínculo afetivo. O vínculo proporciona uma aproximação com a subjetividade do outro. Movido pelo vínculo, o estudante mantém uma atitude ética de zelo, de respeito, de preocupação com os problemas que a família acompanhada vivencia e de busca por intervir nesses dilemas. Conforme Zoboli10, como um elemento ético, o vínculo possibilita a sensibilidade com a experiência humana. Ele permite uma relação de compreensão com o outro. Permite também que a subjetividade do estudante se aproxime da subjetividade da pessoa visitada, e que ela seja compreendida em seu contexto de vida.

Esse vínculo está presente em todo o percurso do estudante, desde suas ações de cuidado com o indivíduo e a família, até sua atuação comunitária, numa perspectiva política, e mostrou ter uma grande 
implicação ética. A partir dele, os participantes do PEPASF se aproximam, emocional e racionalmente, dos sentimentos, interesses e lógicas dos moradores, gerando uma percepção ampliada e sensível de sua realidade subjetiva e material. Essa percepção passa a ser orientadora de seus gestos educativos e de cuidado. O vínculo cria mais motivação e um canal afetivo para ampliar-se essa percepção sutil da realidade, que torna o encontro educativo e de cuidado capaz de fornecer elementos orientadores de um agir direcionado ao benefício dessas pessoas.

Envolvidos pelo vínculo afetivo, observamos que estudantes procuram valorizar a subjetividade dos indivíduos e famílias, em suas ações de cuidado. Vai se aprendendo que uma determinada forma de trazer a emoção para o agir profissional não só é legítima, como extremamente importante. Os estudantes percebem que pequenos gestos guiados pela sensibilidade e pela intuição são bastante significativos na relação com o indivíduo em sofrimento. Percebem a força da valorização da subjetividade humana em seu agir ético com os indivíduos e as famílias que acompanham. Pode-se observar isso no seguinte trecho do depoimento:

"A gente sentou com ela naquele momento, e ela não disse absolutamente uma palavra. Mas, a gente confortou; a única coisa que a gente fez foi realmente abraçar e lá ficar vários minutos com ela, assim, abraçada. Perguntamos se ela queria falar, mas ela só fazia chorar. Eu acho que teve uma questão ética ali, de você respeitar o que ela estava sentindo, perceber, ter aquela sensibilidade e ficar junto". (E4)

Movidos pela sensibilidade do momento e pela intuição, alguns estudantes abraçaram a mulher acompanhada, demonstrando o seu apoio, a sua compreensão, a sua emoção. Esses gestos são geradores de mudanças, e os estudantes sabem da força que eles têm na promoção da saúde das pessoas.

Alguns estudantes das fases iniciais de seus cursos de graduação ficam perplexos, pois, mesmo com pouca formação técnica, sentem-se capazes de ajudar na solução de problemas vivenciados. Isso os motiva a dedicarem-se ao acompanhamento da família, que, por sua vez, passa a gostar cada vez mais da visita semanal. A menor formação técnica dos estudantes das fases iniciais de seu curso contribui para que fiquem mais disponíveis para se envolverem com as várias dimensões dos problemas dos moradores e não apenas nas dimensões em que têm um saber técnico profissional já aprendido e treinado, como tende a acontecer nos estudantes que se inserem no Projeto mais no final de seus cursos $^{11}$. Há uma pedagogia não explícita nos cursos de saúde que vai formatando o olhar do estudante para valorizar e considerar apenas os detalhes do corpo para qual sua profissão tem um agir técnico ${ }^{12}$. Os estudantes que permanecem no Projeto, ao longo de seu curso, vão conseguindo ajustar os caminhos da articulação dos recursos técnicos aprendidos às necessidades mais gerais dos moradores.

A valorização da subjetividade do adoecimento humano, com toda sua complexidade e singularidade, contrapõe-se à orientação presente no modelo biomédico, uma vez que, com sua racionalidade, trata da objetividade da doença, com a exclusão de toda subjetividade que envolve esse processo ${ }^{13}$. Assim, a valorização da subjetividade, da emoção, no cuidado em saúde, turvaria a objetividade lógica que deve orientar a conduta profissional para que alcance um melhor benefício para as pessoas em cuidado. Nessa perspectiva, o vínculo emocional com o sujeito do cuidado pode ser entendido como não ético.

No entanto, no Projeto, vai se percebendo a potência educativa e terapêutica de uma inteligência emocional presente em todos os estudantes e que tende a ser reprimida na formação universitária usual. Os estudantes se surpreendem com sua capacidade de contribuir para a solução de problemas complexos com ajuda da emoção, da sensibilidade e da intuição e não apenas através da razão. $O$ Projeto é uma oportunidade de se elaborar a inteligência emocional, pela possibilidade de uma relação continuada e franca com as pessoas em cuidado e pela possibilidade de problematização coletiva dos atos praticados. Vai se descobrindo a ética de determinado modo de agir emocionado.

Cabe ressaltar que a valorização da subjetividade humana tem sido tema de crescentes debates no campo da ética. Estudos referem sobre o tema da ética na saúde, associando-o à importância da subjetividade humana, da afetividade, nas ações de cuidado $13,14,15,16$. É atribuída, principalmente, à influência do modelo biomédico no cuidado em saúde, o distanciamento para 
com a subjetividade humana na assistência à saúde, porém há uma necessidade de que a emoção, o toque, a escuta e a presença amiga façam parte do cuidado em saúde.

Portanto, na experiência realizada no PEPASF, estudantes têm a oportunidade de experienciar aspectos que fazem parte do debate da ética na atualidade, como a valorização da subjetividade nas práticas de cuidado em saúde. Ao valorizar esse aspecto em suas ações, contribui para transpor a perspectiva do paradigma biomédico na assistência, visto que procura atender a uma concepção integralizadora no cuidado à população acompanhada no âmbito comunitário.

O vínculo afetivo, elemento tão ressaltado na experiência do PEPASF, é uma dimensão do diálogo freireano. Um diálogo que vai além da troca de conhecimentos e da negociação racional de interesses e de projetos. Esse diálogo, que busca estratégias para se tornar horizontal, superando os silenciamentos impostos pelas relações de opressão e humilhação consolidadas na sociedade, é a base para a estruturação do caminho ético de condução das ações educativas e de cuidado nas práticas de Educação Popular. Trata-se, ainda, de um diálogo que não se esgota no encontro, mas que se aprofunda e se desdobra em pesquisas e estudos pela problematização de estranhamentos, dificuldades e contradições, buscando ampliar a compreensão pela correlação com dinâmicas sociais, políticas e ambientais globais. Um diálogo que se prolonga no agir transformador conjunto sobre a realidade problematizada em um processo contínuo de reflexão, ação, reflexão, ação...

A ética na Educação Popular em Saúde é, portanto, definida essencialmente na relação de diálogo. Como elemento ético, o diálogo está voltado à busca pela utopia de construção de uma sociedade transformada, onde os sujeitos subalternos possam ser protagonistas, pessoas participativas e atuantes política e socialmente. O diálogo encontra-se implicado na construção desse protagonismo. Conforme Melo Neto ${ }^{17}$, o diálogo é considerado o elemento ético básico da formulação freireana e está relacionado a um projeto de emancipação. Como expressa o relato a seguir:

“Essa é uma comunidade, um grupo de pessoas que tem seu jeito de viver, que tem violência e miséria, mas que também tem sabedoria e alegria [...]. Daí vem o aprendizado que tive no Projeto, com a ética: é importante você descobrir também que aquelas pessoas, com os próprios "pés", podem melhorar de vida. [...] A gente descobre que pode construir através do diálogo, da problematização da realidade, processos de estímulos para que ela própria possa se reerguer e construir a sua vida e melhorar, não apenas sozinha. Essa não é a ética do individuo; é a ética coletiva, da comunidade!". (E2)

Entretanto, para que as pessoas se tornem participativas, atuantes e protagonistas e possam coletivamente construir sua emancipação, essa relação dialogada se faz de forma específica. Nesse modo ético de diálogo, são criadas condições propícias para que as pessoas em cuidado ou os educandos expressem os problemas, as necessidades, os sofrimentos que experimentam em sua cotidianidade. As pessoas marcadas pelo sofrimento, pela subalternidade, em geral, apresentam dificuldades de se expressar ou de elaborar um discurso claro e afirmativo. É preciso criar dinâmicas para que as pessoas silenciadas falem; é necessário promover um ambiente afetivo para que se sintam à vontade para construir uma relação amorosa, para que se percebam acolhidos e à vontade para explicitar suas opiniões.

Não basta, porém, anunciar a vontade de construir relações baseadas no diálogo. Ele é difícil. A Educação Popular é um saber de superação dos bloqueios e das dificuldades do diálogo educativo com pessoas e grupos sociais marcados por pobreza, subalternidade, opressão e marginalidade. Esse saber é trazido para o Projeto pelos professores, pelas lideranças comunitárias, pelos estudantes mais antigos e pelos estudos bibliográficos. Sem esse saber, o diálogo e o vínculo afetivo não aconteceriam no PEPASF. Apesar de parecerem ser espontâneos e de fluírem naturalmente para muitos estudantes, eles são frutos de uma longa e difícil construção pedagógica, que foi consolidando atitudes e perspectivas de abordagem na cultura do Projeto. No jogo de tentativas, erros e acertos, atitudes e estratégias fortalecedoras do diálogo foram sendo reforçadas e aperfeiçoadas.

A metodologia problematizadora da Educação Popular encontra-se implicada nesse processo. Nesse sentido, as situações verbalizadas mediante o diálogo, geram problematizações que vão originar novas 
elaborações sobre a realidade. O diálogo se aprofunda pela problematização, com uma perspectiva ética importante para a população, pois é feita, valorizando seus saberes, suas lógicas e seus interesses e não apenas trazendo reflexões do saber acadêmico ou dos professores e dos estudantes. Todos são acolhidos indistintamente e têm a oportunidade de participar com suas ideias a respeito da situação analisada. Essa é uma atitude ética que se busca fazer sem autoritarismos ou imposição. Não se procura apenas encontrar melhores entendimentos e soluções, mas também fortalecer o protagonismo dos moradores. O protagonismo político passa pelo protagonismo cognitivo. Assim, a partir da problematização coletiva da realidade, a situação vivenciada é discutida coletivamente e, em conjunto, são delineadas as formas mais éticas de organizar o cuidado em saúde para esses sujeitos. Procura-se construir uma nova forma de organizar a vida familiar e social, de maneira participativa. Esse construir "com", e não "para" eles, tem muitas implicações nos resultados obtidos.

Outra dimensão ética da Educação Popular é a ampla valorização da dimensão política no processo pedagógico. Não se buscam apenas compreender e encontrar soluções para os problemas pessoais e comunitários encontrados, mas enfrentá-los de um modo que fortaleçam as redes locais de solidariedade, as organizações comunitárias e articulações com os movimentos sociais mais amplos, tendo em vista a conquista da justiça social de maneira participativa. Os estudantes e professores se preocupam em apoiar politicamente a comunidade em suas reivindicações políticas, sabendo que elas se ligam a lutas mais gerais da sociedade.

Nesse contexto, destaca-se o trecho do seguinte discurso:

“O apoio do Projeto às lutas comunitárias é uma coisa social. Foi assim na luta pela creche, para resolver a questão do lixo, a questão da história do Programa Saúde da Família; tudo isso foram lutas com participação do Projeto. [...] isso passa pela ética da libertação, pela intencionalidade política de ajudar as pessoas a se libertarem e da justiça social". (P4)

Esse discurso demonstra o compromisso de extensionistas com as aspirações e os interesses da comunidade, numa atitude ética condizente com a intencionalidade política da Educação Popular, de contribuir para transformar a realidade carente onde vivem; unir esforços no sentido de colaborar para conquistar a igualdade de oportunidades e a justiça social. É uma prática educativa que, como Freire ${ }^{3}$ considera, está a serviço da decisão, da ruptura, da opção, da reorientação da ação sobre a realidade com vistas a transformá-la.

Essa é uma ética que se tece na atitude de estímulo à formação do protagonismo social dessa população, para que se sinta altiva e capaz de buscar a conquista de direitos sociais (acesso à saúde, à educação, à moradia, entre outros) e de justiça. Uma justiça que não vem do reconhecimento de gestores das políticas sociais, mas que se forja na base, isto é, que nasce da participação e da luta política comunitária.

A luta política na Educação Popular em Saúde condiz com o pensamento ético freireano, ao evidenciar a valorização de uma ética universal que luta pela concretização dos direitos humanos:

Faz parte da ética universal do ser humano, a luta em favor dos famintos, [...] a briga em favor dos direitos humanos, onde quer que ela se trave. Do direito de ir e vir, do direito de comer, de vestir, de dizer a palavra, de amar, de escolher, de estudar, de trabalhar; do direito de crer e de não crer, do direito à segurança e à paz ${ }^{18}$.

Nesse sentido, norteado pela Educação Popular, o PEPASF oportuniza a estudantes da área da saúde a busca pela concretização de uma ética universal do ser humano, em favor de sua dignidade e dos seus direitos. Essa experiência proporciona aos estudantes a compreensão de que a saúde não significa apenas a ausência de doenças, mas também ter casa para morar, trabalho, educação, alimento, afetividade, entre outros, e que é preciso lutar para que direitos humanos se concretizem e a população empobrecida possa direcionar-se para uma vida digna, o que requer a reorganização da vida política e econômica da sociedade. 
A concepção política da Educação Popular, portanto, pode ser considerada um grande diferencial para a ética na saúde. Traz para o debate atual da ética uma ampliação que supera a preocupação com as relações interpessoais de cuidado, mediante uma perspectiva de ética voltada para uma dimensão socioafetiva.

Vale ressaltar que nem todos os estudantes do PEPASF se envolvem nas lutas mais amplas pela justiça. Alguns extensionistas desenvolvem um sentimento humanitário, indignado, em relação aos problemas vivenciados com a população comunitária. Esse sentimento os motiva a participar e apoiá-los na luta política pela conquista de direitos sociais que lhes são legítimos, tais como acesso a serviço de saúde e à educação, moradia adequada, entre outros. Esses estudantes vinculam-se afetivamente não apenas às famílias que acompanharam ou à dinâmica política da comunidade Maria de Nazaré; apresentam uma vinculação que tende a exceder esse cenário de atuação, algumas vezes desdobrando-se para participação em outros movimentos políticos. O afeto construído tende a se ampliar para uma vinculação de maior intensidade, permeada por um sentimento amoroso que chega dentro do processo, mas não é sentido por todos os estudantes nem na mesma intensidade. É algo que envolve muita afinidade e dedicação a esse trabalho no contexto da Educação Popular; um vínculo amoroso com a causa dos oprimidos; um amor humanitário, universal, em favor da valorização da dignidade humana, do respeito à vida, da luta pela concretização da justiça. Esse sentimento foi citado no seguinte discurso:

"Cada momento que a gente passa na casa daquelas famílias, a ética está sempre regendo nossas vidas. Posso citar a ética da luta por justiça social que tem a ver com a ética do amor; a ética da liberdade; a ética da autonomia, que tem a ver com a liberdade; a ética do cuidado que está ligada a preservação da vida". (P3)

Este estudo tem frisado muito a importância do vínculo afetivo na estruturação de uma ética definida na relação de diálogo com as classes populares. Esse vínculo afetivo começa com o encantamento com a criatividade popular, o carinho como são tratados pelos moradores, o fascínio pela surpreendente diversidade de caminhos de vida presentes naquela comunidade, os desafios teóricos trazidos pelas situações com que se deparam e os consequentes aprendizados, a gratidão das pessoas acompanhadas e o clima de amizade e de alegria que é criado nesse trabalho. Mas esse vínculo vai se aprofundando. Situações de dificuldade, ingratidão, tensão, conflito e frustração surgem, criando períodos sem esses reforços. Tempos áridos, que desanimam alguns, mas fazem outros estudantes descobrirem estar vinculados afetivamente para além das emoções do presente. Um vínculo mais visceral e mais atávico que os aproxima de um compromisso não apenas com os moradores mais próximos, mas com as classes populares em geral. Esse vínculo mais profundo e amplo é mais bem expresso pelos conceitos de amorosidade e amor, muito presentes na teoria freireana.

A amorosidade percorre a obra de Freire e se materializa no afeto como compromisso com o outro. É um sentimento que envolve a solidariedade, a humildade, o respeito ao outro, o acolhimento às diferenças. "É uma amorosidade compartilhada que proporciona dignidade coletiva e utópicas esperanças em que a vida é referência para viver com justiça nesse mundo" ${ }^{19}$. A amorosidade freireana, portanto, relaciona-se a uma perspectiva coletiva, universal, de busca pela justiça, pelo respeito à dignidade humana.

O amor vem sendo motivo de objeto de reflexão filosófica desde a Antiguidade até a Contemporaneidade. Segundo Abbagnano ${ }^{20}$, Platão foi quem primeiro deu tratamento filosófico ao amor. Suas obras, "O Banquete" e "Fedro", destacaram-se como estudos filosóficos sobre esse sentimento. Desde a Grécia Antiga, o amor vem sendo analisado por pensadores de diversas correntes filosóficas como uma manifestação, na realidade humana, de um princípio transcendente que orienta o cosmo. Na Contemporaneidade, a Psicologia se tornou outro campo teórico que muito tem valorizado o seu estudo. Recentemente, a Neurobiologia tornou-se outro campo teórico inovador de seu estudo.

É oportuno destacar que o amor é um sentimento simples de se entender por ser uma realidade existencial universal e, ao mesmo tempo, pouco preciso nas descrições teóricas, por assumir formas tão diferentes no cotidiano da vida humana. Ferreira ${ }^{21}$ afirma que o amor compreende 
diversos significados: sentimento de dedicação absoluta a outro ser ou a uma coisa; sentimento de afeto; amizade, carinho, simpatia, ternura; muito cuidado, zelo; sentimento ardente de uma pessoa por outra; adoração, amor a Deus; inclinação ou apego profundo a algum valor ou a alguma coisa que proporcione prazer. Há o amor de mãe, dos casais, dos místicos, dos poetas, dos prostíbulos, do comércio preocupado com a venda de presentes, de irmãos, dos políticos populistas, etc. A grande valorização do amor romântico entre os casais, na cultura contemporânea, tem criado uma referência de compreensão mais forte que tende a torná-lo um conceito carregado de grande idealização, confundindo outras perspectivas de compreensão. Trata-se, por isso, de um conceito importante no pensamento freireano, que vem sendo evitado de ser analisado mais claramente nos estudos sobre a Educação Popular. Nesses estudos, há uma tendência de explicitar, principalmente, sua dimensão de compromisso, menosprezando suas dimensões afetivas, que este estudo mostrou serem fundamentais.

$\mathrm{Na}$ obra de Paulo Freire, os conceitos amor e amorosidade estão muito presentes. São fortemente influenciados pelo Cristianismo que professava, mais precisamente pela perspectiva teológica que, na década de 1970, passou a ser denominada de Teologia da Libertação. Em entrevista concedida à Revista Tempo e Presença, Freire assim se expressou sobre sua ligação com o Cristo:

[...] a prática pedagógica a que me entreguei desde a minha juventude, no caminho libertador, teve muito a ver com minha opção cristã. Certa vez eu disse numa entrevista que, muito moço ainda, eu fui aos morros do Recife, às zonas rurais, por causa de certa intimidade com o Cristo [...]. Chegando lá, a realidade dramática e desafiante do povo me remeteu a Marx, a sua leitura e estudo. Mas não deixei jamais de continuar me encontrando com o Cristo nas esquinas das favelas ${ }^{22}$.

Nessa entrevista, Freire evidencia a ligação de sua prática pedagógica libertadora com sua opção cristã. Em outras palavras: sua opção cristã encontra-se ligada ao caminho libertador dos pobres de sua condição de oprimidos, de explorados.

A opção cristã freireana remete ao cristianismo social, tal como assumido pela Teologia da Libertação ${ }^{23}$. Esta Teologia propõe o engajamento político dos cristãos na construção de uma sociedade justa e solidária. Considera o pobre, não como um objeto de caridade, mas sujeito de sua própria libertação, protagonista de sua história. As concepções freireanas apontam para esse sentido, visto que Freire expressa uma prática educativa libertadora, voltada para uma concepção crítica e problematizadora da realidade, com vistas à conscientização coletiva e à luta política pela concretização de mudanças. Conforme Silva ${ }^{22}$, a perspectiva cristã expressa por Freire encontra-se vinculada ao sentimento de amor humanitário à pobreza, o qual se revela no compromisso com as classes empobrecidas, com a construção de sua libertação.

Nesse contexto, um dos professores entrevistados assim se reportou:

"A Educação Popular é esse referencial para a gente seguir os princípios éticos da autonomia, da intencionalidade política, da busca por mudanças. Acho que essa ética se encontra muito ligada com o cristianismo, com os princípios morais, não no sentido próprio da moralidade, mas no sentido de princípios que norteiam a vida". (P1)

Essa perspectiva cristã não está presente apenas em Paulo Freire. Muitos dos militantes da Educação Popular são cristãos. A Educação Popular se expandiu muito vinculada às ações pastorais das igrejas cristãs da América Latina. Muitos dos professores e estudantes do PEPASF são cristãos e frequentemente expressam o vínculo entre suas estratégias de ação e sua concepção religiosa.

A pouca legitimidade, no ambiente científico, de trazer a perspectiva religiosa e espiritual para a discussão acadêmica pode estar dificultando a compreensão do conceito de amor na Educação Popular. Talvez por isso seja importante recorrer à teologia cristã para entender melhor o pensamento de Paulo Freire e de muitos educadores populares sobre o amor.

No Cristianismo, o amor também é encarado como princípio transcendente que orienta o cosmo. Seria a forma de o divino se revelar no humano. A primeira carta de João, apóstolo de 
Jesus, destaca que devemos amar uns aos outros, pois o amor vem de Deus e todo aquele que ama, nasceu de Deus e conhece a Deus, porque Deus é Amor. Esta afirmação é base para se entender a antropologia cristã, ou seja, o conceito cristão do ser humano, que teria sido criado à imagem e semelhança de Deus. Assim, para a antropologia cristã, a realidade mais essencial do ser humano é o amor. A história humana seria, nessa perspectiva, formada pelas vicissitudes e peripécias do amor e do desamor. As maiores conquistas e vitórias são as do amor, assim como os erros e as derrotas. A ética cristã é fortemente marcada por essa perspectiva. Paulo de Tarso (5-67 d.C.), conhecido entre os cristãos como São Paulo e autor de textos de imensa influência em todas as igrejas cristãs até na contemporaneidade, escreve em sua Carta aos Romanos que o amor relaciona-se ao pleno cumprimento da Lei. O desafio da ética cristã seria aprender a amar a partir da referência de Jesus de Nazaré24.

A Psicanálise tem evidenciado a força da dimensão inconsciente no ser humano, mostrando a incapacidade da consciência e da objetividade racional governarem todo o seu agir. A espiritualidade cristã seria uma forma de acolher e modular essa dinâmica inconsciente em direção ao amor para que todo o ser, e não apenas a consciência lógica, atue socialmente ${ }^{24}$.

Nessa perspectiva cristã, a amorosidade não seria apenas uma metodologia para o diálogo mais intenso, mas um fim em si mesmo. Não se busca apenas uma sociedade justa, participativa e sem marginalizados ou oprimidos, mas uma sociedade amorosa, pois só assim o ser humano se realizaria plenamente. Paulo de Tarso expressa bem essa perspectiva cristã sobre o amor em sua Primeira Carta aos Coríntios:

[...] ainda que tivesse o dom da profecia, o conhecimento de todos os mistérios e de toda a ciência; ainda que eu tivesse toda a fé, a ponto de transportar montanhas, se não tivesse o amor, eu não seria nada. Ainda que eu distribuísse todos os meus bens aos famintos, ainda que entregasse o meu corpo às chamas, se não tivesse o amor, nada disso adiantaria ${ }^{25}$.

A amorosidade social e radicalmente difundida seria um princípio ético dessa perspectiva cristã, tão presente na Educação Popular. Luta-se por justiça, protagonismo e participação de todos na definição dos rumos da sociedade, pela equidade e pelo fim da miséria, mas tudo com amor e para o amor. Trata-se, sem dúvida, de uma diferenciação de muitas perspectivas éticas emancipatórias que se centram em projetos de reorganização das relações políticas e econômicas concretas e de suas organizações institucionais.

O desenvolvimento do sentimento de amor, por alguns estudantes, durante sua caminhada no Projeto, traz uma significação ética importante associada ao benefício que se quer alcançar mediante o apoio e a participação na busca pela concretização de mudanças na realidade da população comunitária. Motivados pela amorosidade, eles solidarizam-se com as famílias e com a população comunitária, unindo-se com elas, na luta por melhores perspectivas de vida e de saúde, por justiça social. Eles demonstram alegria com as conquistas e entristecem-se com as dificuldades enfrentadas pelas pessoas que ali moram, na luta pela sobrevivência.

Conforme Freire ${ }^{26}$, o amor relaciona-se ao compromisso com a humanidade. Para ele, o ato de amar está em comprometer-se com a causa da libertação dos oprimidos, onde quer que eles estejam. Nesse sentido, a prática educativa freireana expressa um amor compromissado com as classes oprimidas em uma perspectiva libertadora, que impulsiona a população a problematizar as situações de opressão que vivenciam e investe na formação do protagonismo dos sujeitos e dos grupos, tendo em vista a intencionalidade política de transformar a realidade opressora vivenciada.

Nessa perspectiva, em se tratando da proposta ética da Educação Popular em Saúde experienciada pelos estudantes, podemos perceber que a presença da amorosidade gera compromisso com a população comunitária, com as suas reivindicações, com as suas necessidades. A valorização desse sentimento no debate da ética em saúde pode ser considerada uma inovação da discussão do que se busca através do trabalho de promoção da saúde. 


\section{Considerações finais}

O desenvolvimento deste estudo revelou a importância da formação ética oportunizada pelo PEPASF para a estruturação do agir ético de futuros profissionais atuantes no campo da saúde. Este agir ético, baseado no vínculo afetivo, na amorosidade, no diálogo problematizador e na busca pela justiça social, traz uma concepção diferenciada para a ética na saúde na atualidade, que ainda se encontra muito articulada ao cumprimento de códigos de ética e à valorização do modelo biologicista centrado na doença, nas técnicas e na racionalidade científica. Além disso, essa experiência demonstrou que há uma passagem da ética centrada nas relações interpessoais, muito comum nas ações em saúde, para uma ética voltada para uma ação social efetiva.

Embora a ética descrita neste estudo não seja absorvida por todos os estudantes, a experiência oportunizada pelo PEPASF tem contribuído para formar estudantes que seguem hoje, na vida profissional, como pessoas atuantes numa perspectiva transformadora. Nesse sentido, se queremos investir em uma formação ética que tenha fortes influências da Educação Popular, precisamos procurar conquistar, por meios administrativos institucionais e pela melhor sistematização teórica, a incorporação mais abrangente da Educação Popular no ensino em saúde. Desse modo, a formação ética evidenciada neste estudo poderá ser expandida, trazendo uma concepção de ética diferenciada para a saúde pública, pautada em valores humanos.

\section{Referências}

1. Vásquez AS. Ética. 30a ed. Rio de Janeiro: Civilização Brasileira; 2008.

2. Holliday, OJ. Ressignifiquemos as propostas e práticas de Educação Popular perante os desafios históricos contemporâneos. In: Pontual P, Ireland T, organizadores. Educação Popular na América Latina: diálogos e perspectivas. Brasília. DF: Ministério da Educação; 2006. p. 233-9.

3. Freire P. Pedagogia da autonomia: saberes necessários à prática pedagógica. 33a ed. São Paulo: Paz e Terra; 2006.

4. Trombetta S, Trombetta LC. Ética. In: Streck DR, Redin E, Zitkoski JJ, organizadores. Dicionário Paulo Freire. Belo Horizonte: Autêntica; 2008. p. 178-80.

5. Wanderley LEW. Educação Popular: metamorfoses e veredas. São Paulo: Cortez; 2010.

6. Vasconcelos EM. Espiritualidade no cuidado e na educação em saúde. In: Vasconcelos EM, organizador. Espiritualidade no trabalho em saúde. São Paulo: Hucitec; 2006. p. 9-162.

7. Cruz PJSC, organizador. Educação Popular na universidade: reflexões e vivências da Articulação Nacional de Extensão Popular (ANEPOP). São Paulo: Hucitec; 2013. Capítulo x, A extensão popular e seu significado atual para a universidade; p. 21-8.

8. Melo Neto J F. Extensão popular. João Pessoa: Ed. Universitária/UFPB; 2006.

9. Bardin I. Análise de conteúdo. Lisboa: Edições 70; 2010.

10. Zoboli ELCP. Ética do cuidado: uma reflexão sobre o cuidado da pessoa idosa na perspectiva do encontro interpessoal. Saúde Colet. 2007;4(17):158-63.

11. Ribeiro KSQS, Soares JS, Vasconcelos EM, Cruz PJSC, Silva MO, Lira GA. Os primeiros passos de uma experiência de Educação Popular na UFPB. In: Vasconcelos EM, Cruz PJSC, organizadores. Educação Popular na formação universitária: reflexões com base em uma experiência. São Paulo: Hucitec; 2011. p. 64-88.

12. Vasconcelos EM. Educação Popular e o movimento de transformação da formação universitária no campo da saúde. In: Vasconcelos EM, Cruz PJSC, organizadores. Educação Popular na formação universitária: reflexões com base em uma experiência. São Paulo: Hucitec; 2011. p. 363-98. 
13. Guedes CR, Nogueira MI, Camargo Júnior KR. A subjetividade humana como anomalia: contribuições epistemológicas para a crítica do modelo biomédico. Ciênc Saúde Colet. 2006;11(4):1093-103. http://dx.doi.org/10.1590/S1413-81232006000400030

14. Fonseca AM, Campos ACV, Cotta FMP, Borelli LR, Dutra BS, Santana JCB. Reflexões éticas sobre o cuidado humanizado na percepção dos enfermeiros. Ciênc Saúde. 2010;3(1):2-8.

15. Haddad JGV, Zoboli ELCP. O Sistema Único de Saúde e o giro ético necessário na formação do enfermeiro. Mundo Saúde. 2010;34(1):86-91.

16. Fortes PAC. Ética, direito dos usuários e políticas de humanização da atenção à saúde. Saúde Soc. 2004;13(3):30-5. http://dx.doi.org/10.1590/S0104-12902004000300004

17. Melo Neto JF. Educação Popular: enunciados teóricos. João Pessoa: Ed. Universitária/ UFPB; 2004.

18. Freire P. Pedagogia da indignação: cartas pedagógicas e outros escritos. 7a ed. São Paulo: Ed. Unesp; 2000.

19. Fernandes C. Amorosidade. In: Streck DR, Redin E, Zitkoski JJ, organizadores. Dicionário Paulo Freire. Belo Horizonte: Autêntica; 2008. p. 37-9.

20. Abbagnano N. Dicionário de filosofia. 5a ed. São Paulo: Martins Fontes; 2007. Amor; p. 38.

21. Ferreira $\mathrm{ABH}$. Novo dicionário Aurélio da língua portuguesa. 3a ed. Curitiba: Positivo; 2008. Amor; p. 29.

22. Silva NS. Amor e revelação na pedagogia dialógica: diálogo entre Paulo Freire e Juan Luis Segundo [dissertação]. São Paulo: Universidade Metodista de São Paulo; 2009.

23. Calado AJF. Rastreando fontes da utopia freireana: marcas cristãs e marxianas do legado de Paulo Freire. Consciência net. 4 fev 2009 [acesso em: 22 fev 2012]. Disponível em: http://consciencia.net/rastreando-fontes-da-utopia-freireana-marcas-cristas-emarxianas-do-legado-de-paulo-freire-por-alder-julio-ferreira-calado/

24. Storniolo I. O amor, revelação do divino no humano [Internet]. In: Anais do $15^{\circ}$ Congresso Internacional da Associação Junguiana do Brasil; 2007; Atibaia, Brasil. São Paulo: Instituto Junguiano de São Paulo; 2007 [acesso em 4 jan 2012]. p. 5. Disponível em: http://ijusp.org.br/memoria/xv-congresso-internacional-da-ajb-27-a-30092007/.

25. Bíblia sagrada. São Paulo: Paulinas; 2010. 1 Cor 13:2-3.

26. Freire P. Pedagogia do oprimido. 42a ed. São Paulo: Paz e Terra; 2005.

Batista PSS, Vasconcelos EM, Costa SFG. Ética en las acciones educativas y de cuidado en salud orientadas por la educación popular. Interface (Botucatu). 2014; 18 Supl 2:1401-1412.

Este estudio tiene por objetivo analizar la ética, en las acciones educativas y de cuidado, orientada por la Educación Popular en Salud, basándose en la experiencia de extensionistas del Proyecto de Educación Popular y Atención a la Salud de la Familia. Se trata de un estudio cualitativo realizado con diez extensionistas en la Comunidad Maria de Nazaré, João Pessoa, Paraíba - Brasil. Se colectó el material empírico a través de entrevistas y observación de participante, y se analizó por Análisis de Contenido. Las reflexiones evidenciaron la importancia de valorar la subjetividad, la sensibilidad, el protagonista, la vinculación afectiva, la defensa de los derechos humanos y la amorosidad, en la acción ética dirigida a la familia en el cuidado de la salud. Este estudio genera una concepción de ética que transpone la actuación dirigida al cumplimiento de los códigos de ética, usual en la salud.

Palabras clave: Ética. Salud. Cuidado. Educación Popular en Salud. 